\title{
THE MEANING OF AGRICULTURE AND TOURISM ACTIVITIES FOR TENGGER SOCIETY IN WONOKITRI VILLAGE, TOSARI DISTRICT, PASURUAN OF REGENCY
}

\author{
Medea Ramadhani Utomo ${ }^{1}$, Kliwon Hidayat ${ }^{2}$, Yayuk Yuliati² \\ ${ }^{1}$ Postgraduate, Faculty of Agriculture, University of Brawijaya, Veteran Street, Malang 65145, Indonesia \\ ${ }^{2}$ Department of Socioeconomic, Faculty of Agriculture, University of Brawijaya, Veteran Street, Malang \\ 65145, Indonesia
}

Received: 2nd September 2015; Revised: 30th September 2015; Accepted: 10th October 2015

\begin{abstract}
Tengger people's life could not be discharged to nature. Human ecology, a science that describes the interaction of humans and the environment, led to a meaning through the approach of symbolic interactionism and encourage human behavior towards nature. The phenomenon has become the foundation of this research problems. The first objective is reviewing the meaning of farming and tourism services and the relationship between them. The second, linking these two aspects to the behavior of the local community conservation. Third, emphasizing religious activity and its relationship to farming, tourism services, and the local community conservation. In the economic sphere, the relationship activities of farming and tourism services lasted in a synergistic, integrated and encourage one another. As the positive impact, ecotourism was a solution encouraging the Tengger community to give a positive response on the application of conservation agriculture on the dry land, as the efforts to prevent and repair environmental damage. In the culture and religious teachings of Tengger community, there were some important parts of the community, such as certain spells, and the law of Karmapala and the mlaspals ceremony (temple purification) to the safety of humans and nature, at onfarm and tourism activities of live.
\end{abstract}

Keywords: Human ecology; symbolic interactionism; ecotourism; farming; tourism

\section{Introduction}

The use of TNBTS potential by the community is not in parallel with the activity of regional conservation which emphasizes on educating people about the importance of conservation. TNBTS has delivered conservation message mostly through extension activity, either formal or less formal. However, the House of TNBTS still lacks education program that specializes to conservation, especially a specific program that suits to Tengger community. Therefore, the message of conservation cannot be disseminated well (Sayektiningsih, 2008).

The most cultivated farming in Tengger community is vegetable, especially potato and cabbage. Mountainous slope may not be

\footnotetext{
*) Correspondence.

E-mail: medea_ramadhani@yahoo.com

Telp: $+62-85655133512$
}

promising to vegetable growth. The planting of vegetable on steep slope may increase erosion and landslide. Such new farming system only shows the carelessness of environmental management. Some landslides are quite big, moving fast over the slope, and definitely destroying all road infrastructures down below. Water stream is clogged by the avalanche. Heavy load of soil has covered all vegetable lands, but the corn field is not quite destructed.

Huge scale of erosion brings up the unfavorable consequence. The soil becomes harder and unfertile for uncertain long period after erosion. The government starts to lift a prohibition against planting vegetable on steep slope of the hill and to suggest the replacement of potato and cabbage with corn. Recalling that the capacity of crop land is heavily reduced, farmers, especially the poor, are not quite interesting to this option. Besides, the corn only gives them annual income of one fifth or one tenth from 
what they can get if farmland is planted with vegetables (Hefner, 1999).

In addition to the distinctive marker of culture/religion and the cultivation of farmland, tourism sector is also the interesting topic of this research. Natural scenery in Tengger is quite attractive to the outsiders who will then decide Tengger as their tourism destination (ecotourism). Conceptually, ecotourism is a solution to deal with problems related to natural resource conservation at Tengger Region (TNBTS and the surrounding) and a proposed method to increase the economic of Tengger community as the local inhabitant at TNBTS. Therefore, this ecotourism concept accommodates, either directly or indirectly, the principle of natural resource conservation. Based on this concept, natural resource conservation must go along the way with tourism activity at tourism destination. However, such link is not found in Tengger tourist resort (Cochran, 2001).

Taking this overview into account as research background, the objectives of research are: (1) to understand the meaning of farming and tourism as the subsistence and the linkage of these two works; (2) to examine the linkage between the meaning of both works and that of farmland, environmental damage, conservation technology for soil and water, and also to investigate the relation of both works with conservation behavior of farmer community; and (3) to comprehend the linkage between the meaning of traditional/religious activity and the farming, tourism, farmland, environmental damage, and conservation technology for soil and water.

\section{Method of Research}

\subsection{Location and Time of Research}

Research is conducted in Wonokitri Village, Tosari District, Pasuruan Regency. Wonokitri Village is selected as research location because it is the second most active entry gate toward TNBTS Region after Ngadisari Village. The majority of community occupation remains at Farming and Tourism sectors. The schedule of research is 8 months counted from November 2014 to July 2015.

\subsection{Informant Selection Technique}

The technique used to select informant is Snowball Sampling. In this technique, the early number of informant is small and it includes only certain informant. The number is then developed with the information and recommendation given by first or previous informant. Snowball Sampling is aimed to seek and explore information continuously until there is no variation left from information and data.

\subsection{Data Collection Technique}

The technique to collect primary data includes (1) interview consisting of deep interview with key informant and interview using questionnaire with auxiliary informant; and (2) participative observation through which the author explore findings/information at research location.

\subsection{Data Analysis Technique}

Data analysis technique used in this qualitative research is the analysis technique proposed by Miles \& Huberman.

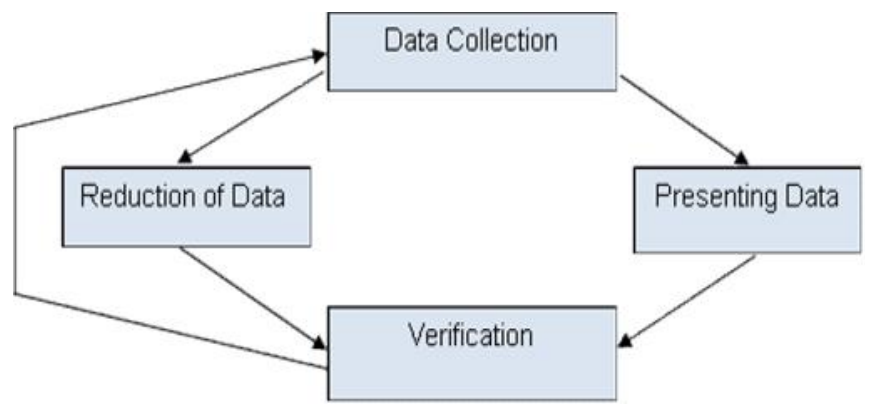

Figure 1. The Model of Qualitative Research Analysis (Miles and Huberman, 1992)

The analysis begins by reviewing all data collected from various sources such as interview note, observation transcription, field script, picture or photograph, and others. During the process of qualitative data analysis, there components are important, respectively, data reduction, data presentation and conclusion.

\section{Result and Discussion}

\subsection{The Meaning of Farming as Subsistence}

Farming is only one part of daily life activities among Tengger farmers because farming is signified by them as the source of subsistence and as the inseparable component of life. The farmers worship the farming prominently. They prefer to undergo farming despite its disadvantageous potential rather than being loser without farming. Being the unemployed or not working in land is causing saturation that influences emotion and spirituality. Therefore, farming keeps farmers 
more convenient with their life and even gives them happiness.

Working on the farmland and taking a profession as farmer are by design to acquire more incomes. It is the most fundamental reason of why farmers consistently cultivate farming. Other than food demand, farming also fulfills other urgent necessities such as child school tuition, unsettled payables, and social costs including annual pray gathering, Jumat Legi pray gathering, wedding event, and circumcise event. More specific, this phenomenon is closely associated with symbolic interactionism.

Symbolic interactionism approach takes a root from the thought of George Herbert Mead. The word "interactionism" is interpreted in such way that this approach is focused upon social interaction. The word "symbolic" concerns with symbols, signs and rationales emerging from the thought of actors. Basically, the so called "meaning" in this research is related with symbols and signs. The symbol is interpreted by the community as the meaning. Indeed, the meaning has preceded the behavior of farmers toward their environment.

\subsection{The Meaning of Tourism as Subsistence}

Some farmers in Tengger community are called as "mixed farmers" because they also work at tourism sector. Tourism is the supplement work that supports the fulfillment of primary demand of the household. However, tourism becomes developing and gives a value that farmers cannot easily deny except in the case of the busiest farming day. In contrast, "pure farmers" only work on the farmland.

Economic factor, or to seek for additional income, is the basic reason why Tengger community is persistent to exploit the opportunity of working at tourism sector. In recent five years, the natural tourism of Bromo Tengger Penanjakan has been developed. Tourism work can give the community the daily income in range between Rp. 15,000 and Rp. 150,000 that may be adequate to fulfill household demand. According to Thomas (1928), human can exploit their free and unique choices, or develop certain part of their life. The asset may also determine the chances of farmers to access and choose the jobs at tourism sector based on their capacity. The upper class of community may invest their asset and choose the profession as the owner of jeep, home stay and villa. Those in middle class are establishing food stalls and souvenir shops selling Tengger merchandise.
Lower class, due to the limited asset, is mostly working as human dispatcher, kibir, peddler, florist, and jacket rent provider.

\subsection{The Meaning of Farmland to Tengger Community}

Poor farmers are greatly harmed in the case of land constriction. The discrepancy occurs between their access to capital and their productive land. Most of them do not consider land ownership as the mandate that must be kept eternally, but the land can be sold, as the best option if necessary, during the period of scarcity.

Moreover, land constriction becomes obvious due to huge necessities for some events such as pray gathering, wedding and circumcise. Other reason for this constriction is the sense of competitiveness among the lower level of community members to show off their opulence. Some farmers perceive that farmland is the ancestral legacy that shall be kept and prepared for their descendants or next generation. Farmland is not only functional as the medium for farming production but also stands as the long-term asset with sacred substance if signified more deeply.

To low class community, they have been self-saturated in seeing their constricted land. Such constriction can reduce their productivity. Mostly, they decide to sell this land and do the exchange with more productive goods such as jeep or pick up vehicles. Conversely, the upper class responds that land represents the expensive highly valued asset which can be useful as the investment for the next generation.

\subsection{The Meaning of Environmental Damage Due To Natural Factor}

Tengger community has signified environmental damage caused by natural factor as a problem. Three problems are known, respectively environmental problem, economical problem, and mental problem. Natural factors that cause environmental damage may include landslide, erosion, flood, extended rainfall and fire. These factors can destroy plants, mainly potato, cultivated on dry farmland in wide scale or even in spread out scale. Being susceptible to these factors, Tengger community then learn to determine the proper time to plant and to rest by keeping pursuant to the safe climate condition. Similar note is also given by Ritzer (1996) who states that human can modify or change any meanings and symbols used in their action and interaction based on their interpretation of 
situation. More specifically, this phenomenon closely associates with symbolic interactionism.

Symbolic interactionism approach is developed from the thought of George Herbert Mead. The word "interactionism" is interpreted in such way to focus upon social interaction. The word "symbolic" concerns with symbols, signs and rationales derived from the thought of actors. Basically, the so called "meaning" in this research is related with symbols and signs. The symbol is then interpreted by the community as the meaning and the meaning initiates the behavior of farmers toward their environment.

\subsection{The Meaning of Environmental Damage Due To Human Factor}

This phenomenon is correlated with the thought of Bennett (1976) who says that environment and environmental function cannot be erased from the influence of human in manipulating natural resource usage for their personal interest or even for the favor of their environment. As previously cited by Tucker quoted in Aryadi (2012), ecosystem is an environmental space where all interactions and reciprocal relations develop between life creatures (including human) and physical environments. Human acts certain way with various motives. Such motives may be selfinterest or due to persuasion of other. Some human actions can destruct the environment and such actions are usually urged by self-interest.

Human treatment to nature is quite smaller or incompatible to the treatment of nature to human which the scale is always beyond human imagination. If human does making holes on their environment, the nature may threaten to produce several pits in the farmland. What has been destructed by human to the nature is not big trouble, but what can be done by the nature is always giving huge impact. Human actions that damage the environment may include intentionally impairment, stealing, burning, plant destruction, and mistakenly littering. Such actions can be minimized because Tengger community is known for tolerance, honesty, harmony, avoiding dispute, and emphasizing kinship.

\subsection{The Meaning of Conservation Farming to Tengger Community}

Ritzer (1996) suggests a tenet of symbolic interactionism, which states that human thinking capacity is developed through social interaction, especially social process. Through this interaction, what is previously less understood becomes understandable, and what is previously not important will become important.

Tengger community has signified the conservation as important. It includes physical conservation and planting conservation. Physical conservation involves the correction of sewage and pipeline, and the construction of terrace, water reservoir and plengsengan. Planting conservation is associated with planting reinforce plants, peripheral plants, filler plants and pest controller plants. This planting conservation may be quite useful to prevent environmental damage around farmland in Wonokitri Village.

When conservation and tourism issues are highly integrated, the community finds difficulty in dividing the job, in sharing the outcome, and in dealing with conflicts. Conservation activity is indeed the responsibility of farmers because conservation is a part of farming, whereas tourism activity is the realm of tourism workers. This paradigm is too apparent which means that the community still gives less support to environmental management based on ecotourism. Conservation farming seems difficult to be associated with tourism potential.

\subsection{The Meaning of Religion to Tengger Community}

Mead quoted by Raho (2002) has asserted that human thinking capacity is developed through their socialization from childhood to adulthood. Symbolic interactionism approach explains that socialization is a dynamic process. In this process, human not only accepts information but also interprets information based on demand.

Tengger farmers follow and learn what is allowed and prohibited. They also understand which one is good and bad since their childhood to adulthood. Their life demand is based on this understanding. It manifests into the routines of Tengger Hinduism such as periodic pray in the shrine, Jumat Legi pray, and specific event for Tengger Hinduism great days such as Kuningan, Galungan, Unan-Unan, Karo, Kasada, Nyepi and others.

Custom ceremonies are distinguished into three kinds, respectively life human ceremony, dead human ceremony and natural human ceremony. Life human ceremony includes wedding, circumcise, and other gathering which invites neighbors. Dead human ceremony involves gathering to give pray for the dead. This gathering is called as Nyewu. Natural human 
ceremony is held in relative with human activity in farmland. It is conducted by putting offerings "patmasari" into the farmland. Kasada is signified as a form of appreciation for the prosperity given by the nature because it will somehow return to the nature.

The belief of Tengger community has underscored that nature is the source of wealth and life. Tengger Hinduism emphasizes on noble and sublime behaviors. Indeed, such behaviors are given more priority than pray ritual. Tengger Hinduism applies Hukum Karma Pala which means that every human must plant good thing to harvest good thing also. Therefore, some people presume that the celebration of Tengger Hinduism great days in glorious way will produce prestige and recognition from other. For example, small party for wedding event is risking someone to be considered as poor or disadvantaged. Religion activity also brings along a very powerful prestige in the eye of Tengger community.

Social identity attributed to Tengger community has brought a signification that Tengger community is a community with a distinctive ritual tradition through which they lean themselves to the protection of Mountain Spirit. They believe that the ancestor of Tengger community is the descendants of Majapahit Kingdom. The term "Tengger", based on their folk legend, comes from the final syllables of the name of their ancestors, Rara Anteng and Jaka Seger (teng and ger).

\subsection{The Linkage of Four Main Aspects}

There is a linkage that connects four main aspects of research, respectively (1) farming activity, (2) tourism activity, (3) religion activity of Tengger Hinduism, and (4) conservation farming activity on farmland in Wonokitri Village.

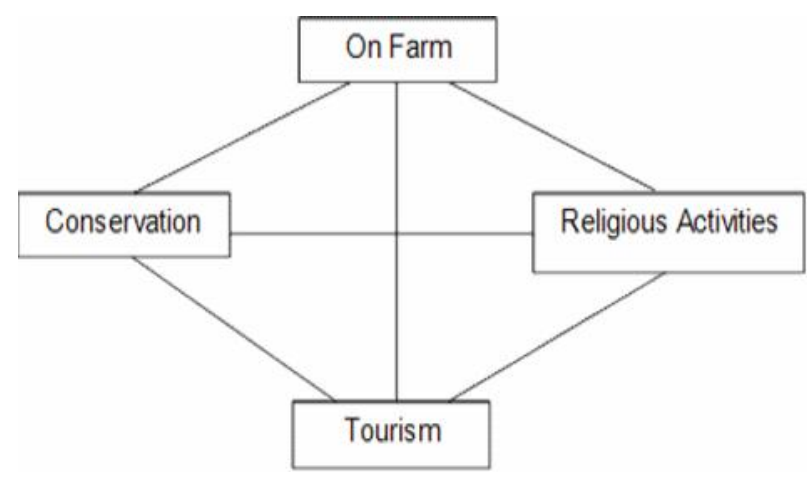

Figure 2. The Linkage of Four Main Aspects as Research Focus
The linkage between farming and tourism is mutualism. First, the outcome from tourism will become alternative support for those with limited capital for farming. Secondly, the actors behind farming and tourism give positive response to conservation, especially those in middle class of community. They show great concern with the environmental damage at their activity spots. Third, strong religiosity is still found among Tengger community who work either as farmer or tourism worker.

\subsection{The Linkage between Religion Meaning and Farming Activity}

It has been signified among Tengger community, especially farmers, that religion activity is a good manner before they go to farmland either for planting, maintenance or harvesting. Lower and middle classes of Tengger community believe that putting the offerings on patmasari in farmland will give safety and feasibility to farming activity at farmland. The offerings are considered helpful to give normal growth to the plant. Those from lower class do not take for granted this belief. They often show a posture of defenseless.

Shrine purification is also correlated with the successful farming activity, especially when farming shall collapse at certain period. Shrine purification is also considered as the precondition to obtain plenitude harvest. Surprisingly, the bad days of farming start to decline and many farmers buy vehicles for their farming transport. Special ritual in shrine purification is mlaspals ceremony. Actually, this ceremony is not only purifying the shrine, but also the ancestral artifacts, sacred buildings and other holly places.

\subsection{The Linkage between Religion Meaning and Tourism Activity}

During the carry out of Kasada ceremony, many visitors come to Bromo to watch over the tradition of Tengger community in celebrating Kasada Great Day and to follow the set of auxiliary rituals. Religion activity is not the part of tourism or even unrelated to tourism activity, but this activity provides attraction and influence to Bromo tourism.

Those in upper and middle class of community perceive that praying or reciting special charm spell are important prefix before starting the work in tourism activity. Serving the guest in tourism also needs smoothness, safety and livelihood. To those in lower class of community, such routines are ignorable because 
they lack of understanding about strong link between tourism and religion activity.

Traditional ceremonies and other rituals are still strongly preserved by Tengger Hinduism community. It may be due to the proximity of their geographic site with Mount Bromo. The existence of Mount Bromo has empowered their faith to the presence of God, called as Hyang Widi. They also convince that Tengger community during the age of Majapahit Kingdom is the solid community despite slight number of population.

Other reality that shows a linkage between custom and tourism world is that life style of Tengger community has indeed been changed with the arrival of visitors or tourists. Some youths are influenced by the appeal style of visitors, but it is only temporary. The spirituality among the youths is not reduced or even unchanged at all although tourism activity is quite crowded. They signify that God has regulated the reward for the life balance and the service provided by Tengger Hinduism community in Wonokitri Village. Their duty, as noble human, is to escort, preserve and exploit the existing chance to produce the better life.

\section{Conclusion}

Farming and tourism activities are signified as the source of life and income and also as the solution to unemployment. Specifically, upper and middle classes of community consider farming as profitable activity. Therefore, they are willing to increase their supporting capacity or to allot their capital for the farming, such as by providing Jeep rental service, setting up food stalls/ souvenir shops, and building home stay and villa. Lower class of community may signify farming activity as the work with uncertain profit but with certain loss. To compensate minimum outcome from farming and to fulfill the household demand, they work at tourism sector as human dispatcher, kibir, peddler, florist, and jacket rent provider.

In relative with conservation behavior among Tengger community, the upper class has signified farmland as the asset that must be cultivated for the next generation. Therefore, they hold tightly this farmland but by disregarding the importance of conservation. Their conservation farming behavior is always trivial. In contrast, some people from lower and middle classes are positively responding the conservation for farmland. However, lower class still signifies farmland as the asset that is exchangeable to more productive goods. Therefore, they often sell this farmland which becomes one reason of land constriction. Related to religion aspect, people from upper class believe that there is linkage between religion activity and nature. This belief may be supported by knowledge and religion understanding that have been built since childhood. In lower class, religion activity has been signified as human duty but without correlation with farming success. Indeed, they do not trust the linkage between religion activity and nature.

Tourism association and village officers shall be involved in supervising, coordinating and evaluating many tourism activities in order to produce orderliness. Both agencies are expected to formulate the ideal organization to accommodate many less organized communities, such as peddlers, human dispatchers and kibir. The government of Village can settle upon the cooperation with Tosari Extension Agency, The Official of Agriculture for Pasuruan Regency, and the related executives, to give priority on the application of conservation technology in mechanical way and to strive for planting on landslide region. Both activities can support the works at farming and tourism sectors. The prominent figures of village and religion who are recognized as Dukun Tengger shall provide mediation for building a linkage between community classes, between groups and between communities. It is an attempt to avoid difference, and also to establish togetherness, harmony, reconciliation, kinship and orderliness among the social life of Tengger community in Wonokitri Village.

\section{References}

[1] Aryadi, M. 2012. Phenomenology of Adaptation to Community Culture. University of Muhammadiyah, Malang.

[2] Beaumont, N. 2013. The Third Criterion of Ecotourism: Are Ecotourists More Concerned About Sustainability Than Other Tourists. University of Southern Queensland, Springfield, Australia.

[3] Eshliki, S. A. 2011. Community Perception of Tourism Impacts and Their Participation in Tourism Planning: A Case Study of Ramsar, Iran. Department of Architecture \& Urbanism, Iranian 
University of Science \& Technology, Tehran, Iran.

[4] John, W. C. 1998. Qualitative Inquiry and Research Design: Choosing Among Five Traditions. London : SAGE Publications.

[5] Maher, P. T. 2003. Tourism and Indigenous Peoples: Issue and Implications. University of Northern British, Columbia.

[6] Na Songkhla, T. 2013. Interactions Between Agro-Tourism and Local Agricultural Resources Management. Southern, Thailand.

[7] Pramita, N. H. 2013. Ethno-botanic of Kasada Ceremony at Tengger Community in Ngadas Village, Poncokusumo District, Malang Regency. Faculty of Mathematic and Natural Science, University of Brawijaya, Malang.

[8] Sagala, L. P. 2008. Eco-tourism Request from Foreign Tourists in National Park of Bromo Tengger Semeru (TNBTS), East Java. Faculty of Forestry, IPB, Bogor.

[9] Sayektiningsih, T. 2008. The Strategy of Conservation Education Development in Tengger Tribe Community in Enclave Village of National Park of Bromo Tengger Semeru. Faculty of Forestry, IPB, Bogor.

[10] Sutarto, A. 2006. Cultural Adventure. The House of Review for Historical and Traditional Values. Yogyakarta. 